\section{P2-424 MILD FOOD INSECURITY IS ASSOCIATED WITH OBESITY AMONG BRAZILIAN WOMEN}

doi:10.1136/jech.2011.142976l.54

${ }^{1} \mathrm{G} \mathrm{Kac},{ }^{*} \mathrm{G}$ Velásquez-Melendez, ${ }^{1} \mathrm{M}$ Shlüssel, ${ }^{4} \mathrm{~A}$ A M da Silva, ${ }^{2} \mathrm{~J} \mathrm{D}$ Lopes-Filho, ${ }^{3}$ A Brito. ${ }^{1}$ Federal University of Rio de Janeiro, Rio de Janeiro, Brazil, ${ }^{2}$ Universidade Federal de Minas Gerais, Minas Gerais, Brazil, ${ }^{3}$ Fluminense Federal University, Rio de Janeiro, Brazil; ${ }^{4}$ Federal University of Maranhão, São Luís, Brazil

Introduction To determine if food insecurity was associated with a higher prevalence of obesity in a large random sample of Brazilian women of reproductive age.

Methods The data were derived from the third edition of the Children's and Women's National Demographic and Health Survey, conducted in 2006-2007. This was a nationally representative cross-sectional study. Obesity $\left(\mathrm{BMI} \geq 30 \mathrm{~kg} / \mathrm{m}^{2}\right)$ was the outcome variable. Associations were measured using crude and adjusted prevalence ratios (PR) with 95\% CI through Poisson regression models taking into account the complex sampling design. The sample included 10226 women from 18 to 45 years.

Results The prevalence of any level of food insecurity measured by the Brazilian Food Insecurity Scale was $40.9 \%$, with 25.5\% light, $10.1 \%$ mild and $5.3 \%$ severe food insecurities. The prevalence of obesity was $17.4 \%$. We found borderline effect of light food insecurity and increased prevalence of obesity in Brazil ( $\mathrm{PR}=1.16 ; 95 \%$ CI 0.98 to 1.38; $p>0.05$ ). Women with mild food insecurity had a higher risk of being obese than their counterparts without food insecurity ( $\mathrm{PR}=1.49$; 95\% CI 1.17 to $1.90 ; \mathrm{p}=0.010$ ), after adjustment for skin colour/ethnicity, years of schooling, macro-region, income, age and marital status.

Conclusion Mild food insecurity was associated with obesity as measured by BMI, even after adjusting for various confounding factors in this large cross-sectional survey performed in a middleincome country undergoing the nutrition transition.

\section{P2-425 ERADICABILITY OF POLIOMYELITIS IN INDIA, NEW EVIDENCE FROM RECENT TRENDS}

doi:10.1136/jech.2011.142976l.55

R Kamath,* V Bhat, D Lobo, S Pattanshetty. Manipal University, Manipal, India

Background In May 1988, the World Health Assembly committed the member nations of the WHO to achieving the goal of global eradication of poliomyelitis. In 2008, only four countries in the world remain polioendemic, down from more than 125 in 1988. The remaining countries are Afghanistan, India, Nigeria and Pakistan. Since 1995, the Ministry of Health and Family Welfare, Government of India has been conducting intensive immunisation and surveillance activities aimed at the complete elimination of poliovirus and paralytic polio.

Objective To analyse the trend of polio cases in India with emphasis on Uttar Pradesh state.

Materials and Methods The records of last 10 years was reviewed and details regarding total AFP cases reported, AFP rate, Non-polio AFP rate, AFP with adequate specimen, total confirmed cases in India and Uttar Pradesh was obtained.

Results The total confirmed cases reported in India in the year 2010 to date are 21 compared to 741 cases in 2009. Out of 741 cases, Uttar Pradesh state contributed 602 cases. Highest number of cases (1600) was reported in the year 2002 compared year 2005 (66 cases). AFP rate was 23.64 in 2009. Percentage with two specimens collected within 14 days was $81 \%$.

Conclusion Incidence of Polio being clustered in a geographically areas. The highest priority is reaching all children in the age group of $0-5$ years. To achieve eradication, high levels of political commitment and focused implementation must be maintained at national, state/provincial and district levels.

\section{P2-426 SMOKING TOBACCO IN PEOPLE LIVING WITH HIV (PLWH)} IN GOMA/DRC

doi:10.1136/jech.2011.142976l.56

${ }^{1} \mathrm{M}$ K Sahani, ${ }^{2} \mathrm{M}$ M Mutumwa, ${ }^{3} \mathrm{G} \mathrm{K}$ Nzay. ${ }^{1}$ Agir Ensemble, NGO, Goma, The Democratic Congo; ${ }^{2}$ Medical Center SOS Survive, Goma, The Democratic Congo; ${ }^{3}$ Agir Ensemble, NGO, Goma, The Democratic Congo

Background Knowing that Tobacco is a big health issue, killing 5.4 millions of people each year. Hypothesis: among PLWH, smokers have more health problems than non smokers.

Objectives To analyse the impact of tobacco in people living with HIV (PLWH), degree of ARV side effects for smokers and non smokers, relevance of literacy on tobacco as public health problem on attitude of PLWH regarding tobacco use.

Methods Retrospective and prospective study realised in GOMA/ DRC. Target: PLWH. Our sample is 200 PLWH constituted by aleatory method taking 2 people among 13 with interval of 6 after the first choice. Prospective: this was to determine the attitude of PLWH regarding tobacco: Statistic test: "comparison of two proportions".

Results Sample of 200 PLWH: 125 females and 75 males; Smokers: 90 (45\%) Non smokers: 110 (55\%). Among 90 smokers: 56 males $(62.2 \%)$ and 34 females $(37.8 \%)$. Smokers have more risk of decreasing immunity than non smokers. Smokers have more risk to develop chronic lung diseases than non smokers. Side effects of ARVs are increased for smokers than non smokers. Smokers have more risk to develop opportunistic infections than people who don't smoke. PLWH are engaged to quit smoking when informed (aware) of bad effects of tobacco but some need assistance for quitting. PLWH who smoke industrial tobacco have more difficulty to quit smoking than people who smoke traditional tobacco.

Conclusions Tobacco use is more dangerous for PLWH than others (HIV-). It is very important to start new approach of collaboration between tobacco activists and HIV activists. Activities anti-tobacco could be integrated to HIV services at all levels: prevention, screening, treatment, etc. Assistance for quitting smoking could be provided to PLWH as well as ARVs. To spread the information that smoking is dangerous to PLWH motivate them to quit smoking.

\section{P2-427 BODY MASS ANALYSIS IN PRIMARY SCHOOL AGE CHILDREN IN LATVIA}

doi:10.1136/jech.2011.142976l.57

H Karklina, ${ }^{*}$ D Krumina, G Knipse, J Valeinis. University of Latvia, Riga, Latvia

Introduction The prevalence of excessive and insufficient body mass in children is increasing worldwide according to epidemiologic researches. There is a risk of health disorder with the fluctuation of body mass.

Aim To determine the current situation in Latvia, estimate the amount of thin and overweight children and calculate Fat Mass Index using the skin fold measurements.

Methods 1025 Latvian youngest grade schoolchildren were selected from 2007 to 2009 and a cross sectional survey carried out using questionnaire and anthropometric methods as well as somatotype analysis. The percentage of body fat was estimated using the sum of two skin folds. Fat mass index (FMI), FFMI (Fat Free Mass Index) and Body Mass Index (BMI) were calculated accordingly. Children were divided into groups to determine the nutrition level using $3 \mathrm{rd}$, 15th, 85th and 97th BMI and FMI percentile values.

Results The results show that the amount of children with extremely low body mass is equally significant with those with adiposity diagnosed using BMI. When using BMI to analyse the changes, children with normal fat percentages show decreased, normal and increased body mass values. 